\title{
The Effects of Chicken Box, Chick Paper Type and Flock Age on Sound Level and Leg Abnormalities in One-Day Old Chicks in the Hatchery
}

\author{
Ahmad SALAHI ${ }^{1}$ Ali K. ESMAILIZADEH ${ }^{2}$ \\ ${ }^{1}$ Raam Toyour Company,Tehran, Iran \\ ${ }^{2}$ Dept. of Animal Science, Faculty of Agriculture, Shahid Bahonar University of Kerman, Kerman, Iran
}

Received (Geliş): 06.08.2014

Accepted (Kabul): 17.09.2014

\begin{abstract}
Chicken box and chick paper are two important factors affecting quality of delivered chicks after hatching and packaging until arrival in rearing farms. In this study, characteristics of 70 samples of chicken boxes collected during two years in four hatcheries in Iran were surveyed. Winter and summer types of chicken boxes each with seven replicates including five chicken boxes were studied. The capacity, length, width, height, weight, area, total ventilation ducts of the boxes in summer and winter cartons were 80 and 100 birds, 59.50 and $59.27 \mathrm{~cm}, 43.44$ and $43.25 \mathrm{~cm}, 13.20$ and $12.04 \mathrm{~cm}, 387$ and $382.3 \mathrm{~g}, 0.685$ and $0.664 \mathrm{~m}^{2}, 204.16171 .28$ $\mathrm{cm}^{2}$, respectively. Allowance space per chicken in chicken box in winter and summer was 1.71 and $2.43 \mathrm{~cm}^{2}$, respectively. The duration of chickens stay at chicken box in summer and winter was 12 and 7.57 hours, respectively.

Significant difference between the height of box, capacity, duration of stay at chicken box, space per chick $(\mathrm{P}<0.0001)$, total ventilation ducts (pores area) for air exchange $(\mathrm{P}<0.05)$ and width of chicken box $(\mathrm{P}<0.014)$ was observed in winter and summer boxes. Effects of chick paper type (rough and smooth) used in chicken box floor on the sound level was significant $(80.50$ and $76.55 \mathrm{~dB}$ for rough and smooth type, respectively; $\mathrm{P}<0.009)$. Effect of flock age on chick weight and sound level was significant $(\mathrm{P}<0.001)$. Sound level in chickens with 26 and 86 weeks of age was 76.10 and $80.95 \mathrm{~dB}$, respectively. Effects of chick paper type on leg damages, total defects in motor organs of chickens and chicken leg stuck under the box divider was significant $(\mathrm{P}<0.001)$. Effects of chick paper type on spraddled (sprawled) leg and redness of feet skin or toe were not significant.
\end{abstract}

Keywords: Chicken box, Chick paper, One-day old chicks, Sound level, Leg damage.

\section{INTRODUCTION}

Chickens cannot self-regulate their body temperature and are sensitive to heat and cold stress. A comfortable temperature for one day-old chicks is approximately 32 to $35^{\circ} \mathrm{C}$ (Malheiros et al., 2000) and average box temperature of $31-35^{\circ} \mathrm{C}$ during ground transportation (Xin and Rieger, 1995). The measured temperatures inside the containers placed in the center of the stack (vertically and horizontally) can be 8$14^{\circ} \mathrm{C}$ warmer than the ambient temperature, while the temperature of the boxes placed on the outer perimeter of the stack are likely closer to the ambient temperature (Henken et al., 1987). Transport conditions in meat chickens may provide useful information to be used in chicken room conditions in hatchery. Arthur (2004) reported that the best temperature for chick room where the boxes containing chicks are stored is $23^{\circ} \mathrm{C}$. Also, it has been reported that the optimal conditions in chicken transport include a temperature range of $24-25^{\circ} \mathrm{C}$, relative humidity of approximately $65 \%$, space allowance of $21-25 \mathrm{~cm}^{2}$ per chick, and travel time of no longer than 48 hours (Mitchell and Kettlewell, 2004; EFSA, 2004; Juul-Madsen and Sqrensen, 2004).

Newer breed of commercial birds have a much higher metabolism rate than older breeds (EFSA, 2004). It is important to avoid high temperatures and keep proper ventilation during transportation of the chicks in order to reduce first week mortality and to reach a better performance (Xin and Rieger, 1995; Joseph and Moran, 2005). Therefore, more information is required about heat production and ventilation requirements and chicken box characteristics to design proper winter and summer chicken boxes.

Chicken meat (eviscerate weight) in world, Asia and Iran at 2010 was 81.75, 28.69 and 1.6 million tones, respectively. Iran had been in raking of 3 in Asia following China and India. Statistics showed that, there were 18572 poultry farms (broiler and layer) in Iran in 2009 and 874 million pieces of oneday old chicken are produced and reared annually in Iran (SCI, 2009). In commercial companies, boxes are stacked one on top of another in tiers, with several boxes per tier and 80 to 100 chicks per box. Assuming 90 chicks per each chicken box, a total of 9.71 million boxes are required for transporting the one-day old chicken in Iran. The aim of the present study was to investigate the effects of chicken box and paper type on the quality of the delivered one-day old chicks.

Generally, bird skins are thinner than mammal and good quality chick is well developed legs that are soft and well hydrated when the toes are extended or stretched. Young chicks kept on the slippery surface suffer from leg problems (Splay Leg), but the knees or hocks of a first class chick will show no signs of 
swelling and be of normal skin color (Pasreform, 2008). Locomotors disturbances of poultry in meat type are more than others. It also increases with age and weight gain of the bird. In some areas, skin is connected to muscle, but the most connections are with skeleton (to hands and feet bones) (King and Mclelland, 1999).

As two kinds of chick paper, roughened and smooth papers, are used for transporting the one-day old birds, another objective of this study was to investigate the effects of chick paper type on leg abnormalities in one day old chicks.

\section{MATERIALS and METHODS}

There were two types of chicken boxes used in winter and summer. The summer cartons were used for four months in warm seasons and the capacity of each box was 80 chicks, while the winter cartons were used for a period of 8 months and the capacity of each

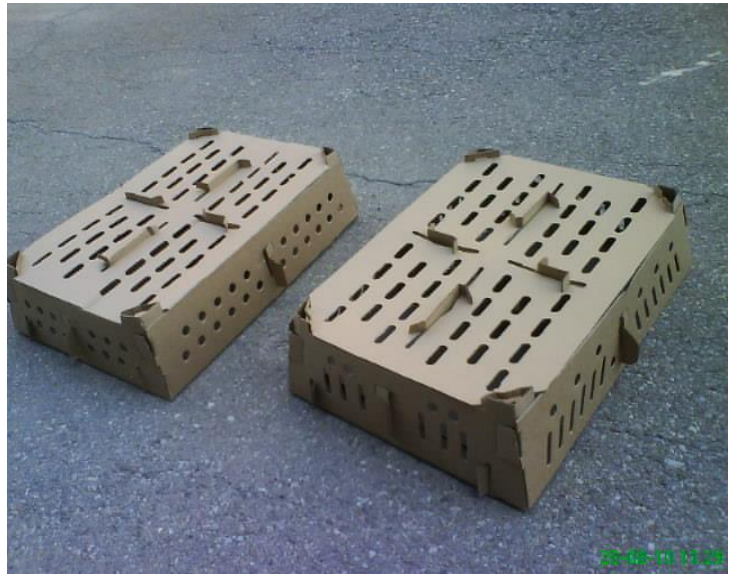

box was 100 chicks. A total of 70 samples of chicken boxes used for broiler chickens from four companies were collected during two years (Figure 1). After collecting the boxes, they were weighed using a pocket professional digital scale with $0.01 \mathrm{~g}$ accuracy. This weight included box body weight, divider, and the lid of carton. Also, the height, length, and width of boxes were measured by a ruler. The area of carton was calculated. In order to calculate the ventilation capacity (air ducts) on the body of a carton, the pore size of each circle was measured with a caliper and then circle area was multiplied by number of ducts. Every chicken box was divided into four equal parts, and then 20 and 25 chicks were put in every part in summer and winter, respectively. After placing chicks in the boxes, average time of chicken stay in cartons was recorded. Chick stay time in boxes started when grading and pulling of chicks from hatcher was finished.

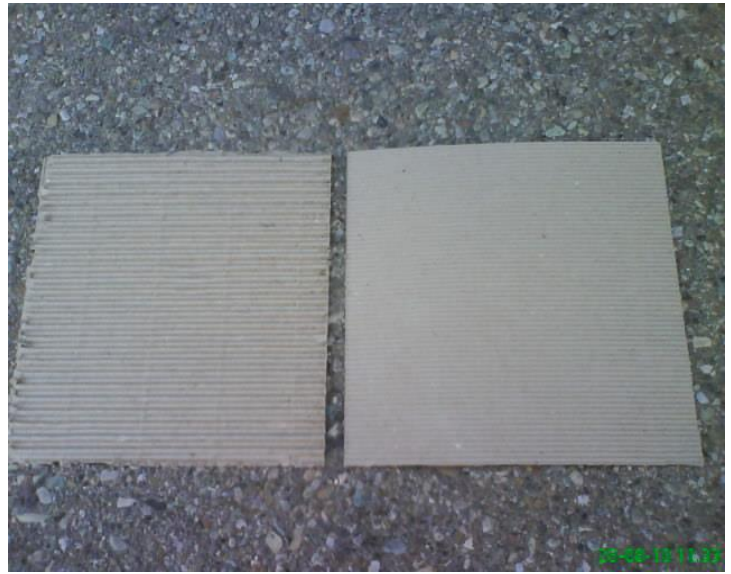

Figure1. Chicken box (left) and chick paper type (Rough and smooth) (right)

In the second study, we classified chick papers into two types, rough and soft (smooth). Width of tracks per channel, at rough and smooth chick papers was 7.24 and $2.77 \mathrm{~mm}$, respectively. Height or thickness of the tracks in the tallest part of chick paper was 4.07 and $1.22 \mathrm{~mm}$ in rough and smooth papers, respectively.

We used a DB 100 sound level meter were made by Kimo company (Kimo, 2010) to measure sound level as it is reliable, easy to use and in accordance with metrology requirements. This instrument could measure a range of $30-130 \mathrm{~dB}$ with a resolution of 0.1 $\mathrm{dB}$. Sound level meter instrument had data integration time from $1 \mathrm{~s}$ to $15 \mathrm{~min}$, but we used 30 second and we recorded mean of information for every chicken box. The units for measuring the loudness of the noise are called decibels or dB (Paulson and et al., 1999; EA, 2005). Measuring of sound level were in a quiet and isolated room at $23^{\circ} \mathrm{C}$ and 12 hours after leaving the Hatcher machines with the help of two technicians.
The probe of the sound level meter was kept exactly at the top of the chicken head. There was no fan or ventilator in the assessment room. Ten chicken boxes from each of the paper types were chosen randomly. There were 100 chicks per chicken box (i.e. 1000 chicks from each of the two paper types. In the third test, effect of chick paper type on leg abnormality was investigated. We selected 260 chicken boxes each box containing 100 chicks. All the chicks were kept 12 hours in chicken box and leg status of the chicks was recorded. In total, 52000 chicks (26000 chicks per paper type) were used in this part of the study.

The data analysis was carried out using GLM procedure of SAS software version 8.0 (SAS Institute, 1999) applying a statistical model containing fixed effects of paper type (two levels) and flock (two levels) and the residual random effect. 


\section{RESULTS}

Summer type chicken box was heavier and longer $(0.23 \mathrm{~cm})$ than winter type, but these differences were not significant. Also height, width and area (spread page) and total ventilation ducts of summer chicken box were greater than the winter type, but only height $(p<0.0001)$ and width of chicken box and total ventilation ducts had significant differences $(p<0.05)$ (Table1). In addition, the results showed that chicken box capacity, space allowance per chick $\left(\mathrm{cm}^{2}\right)$ and duration of chicken stay in box (h) significantly differ between summer and winter type $(\mathrm{P}<0.0001)$ (Table2).

The effect of chick paper type on sound level is given in Table 3. Sound level in the roughed and smooth papers was significantly different $(80.50$ and $76.55 \mathrm{~dB}$, respectively) $(\mathrm{P}<0.001)$. The results indicated that chick weight in flocks with 29 and 86 weeks of ages was 38.87 and $47.34 \mathrm{~g}(\mathrm{P}<0.001)$ while the sound level was 76.10 and $80.95 \mathrm{Db}(\mathrm{P}<0.001)$, respectively (Table 4).

Weights of the chicks kept on different paper types were not significant. However, the effect of chick paper type on leg damages, the total damages in motor organs of the chicks and chick leg stuck under the box divider was significant $(\mathrm{P}<0.001)$. The chicks kept on the roughed papers suffered more from leg defects when compared with those kept on the smooth papers $(\mathrm{P}<0.001)$ (Table 5).

Table 1. Chicken box characteristics and dimension used in Iran Hatcheries

\begin{tabular}{lcccccc}
\hline Season & $\begin{array}{c}\text { Weight (with door and } \\
\text { divider })(\mathrm{g})\end{array}$ & $\begin{array}{c}\text { Length } \\
(\mathrm{cm})\end{array}$ & $\begin{array}{c}\text { Height } \\
(\mathrm{cm})\end{array}$ & $\begin{array}{c}\text { Width } \\
(\mathrm{cm})\end{array}$ & $\begin{array}{c}\text { Area } \\
(\text { spread page }) \\
\left(\mathrm{m}^{2}\right)\end{array}$ & $\begin{array}{c}\text { Total Ventilation } \\
\text { ducts }(\text { except door }) \\
\left(\mathrm{cm}^{2}\right)\end{array}$ \\
\hline Summer & 387 & 59.50 & $13.20 \mathrm{a}$ & $43.44 \mathrm{a}$ & 0.685 & $204.16 \mathrm{a}$ \\
Winter & 382.3 & 59.27 & $12.04 \mathrm{~b}$ & $43.25 \mathrm{~b}$ & 0.664 & $171.28 \mathrm{~b}$ \\
SEM & 8.56 & 0.177 & 0.026 & 0.045 & 8.92 & 9.59 \\
P Value & 0.703 & 0.379 & $<0.0001$ & 0.014 & 0.126 & 0.032 \\
\hline
\end{tabular}

${ }^{\mathrm{a}-\mathrm{b}}$ Means within a column without a common superscript differ significantly $(P \leq 0.05)$.

Table 2. Chicken box capacity, space per chick and duration of stay

\begin{tabular}{lccc}
\hline Treatment & $\begin{array}{c}\text { Capacity } \\
(\text { Number })\end{array}$ & $\begin{array}{c}\text { Space allowance (per chick) } \\
\left(\mathrm{cm}^{2}\right)\end{array}$ & $\begin{array}{c}\text { Duration of chicken stay in box } \\
(\mathrm{h})\end{array}$ \\
\hline Summer & $80 \mathrm{~b}$ & $2.43 \mathrm{a}$ & $12 \mathrm{a}$ \\
\hline Winter & $100 \mathrm{a}$ & $1.71 \mathrm{~b}$ & $7.57 \mathrm{~b}$ \\
\hline SEM & 0 & 0.085 & 0.21 \\
\hline P Value & $<0.0001$ & $<0.0001$ & $<0.0001$ \\
\hline
\end{tabular}

${ }^{\mathrm{a}-\mathrm{b}}$ Means within a column without a common superscript differ significantly $(P \leq 0.05)$.

Table 3. Effect of chick paper type on sound level and weight of day-old chicks

\begin{tabular}{|c|c|c|}
\hline Treatment & Chick weight (g) & Sound level (dB) \\
\hline Rough & 43.15 & $80.50 \mathrm{a}$ \\
\hline Smooth & 43.06 & $76.55 b$ \\
\hline SEM & 0.2131 & 1.027 \\
\hline P Value & 0.764 & 0.0099 \\
\hline
\end{tabular}

${ }^{\mathrm{a}-\mathrm{b}}$ Means within a column without a common superscript differ significantly $(P \leq 0.05)$.

Table 4. Effect of flock age on sound level and weight of day-old chicks

\begin{tabular}{lcc}
\hline Flock Age (week) & Chick weight $(\mathrm{g})$ & Sound level $(\mathrm{dB})$ \\
\hline 86 & $47.34 \mathrm{a}$ & $80.95 \mathrm{a}$ \\
29 & $38.87 \mathrm{~b}$ & $76.10 \mathrm{~b}$ \\
SEM & 0.2131 & 1.027 \\
P Value & 0.0001 & 0.0019 \\
\hline
\end{tabular}

${ }^{\mathrm{a}-\mathrm{b}}$ Means within a column without a common superscript differ significantly $(P \leq 0.05)$ 
Table 5. Effect of chick paper type on leg damages in chicken hatchery

\begin{tabular}{lccccc}
\hline Treatment & $\begin{array}{c}\text { Damage\& } \\
\text { Red hocks } \\
(\%)\end{array}$ & $\begin{array}{c}\text { Spraddled } \\
\text { Legs } \\
(\%)\end{array}$ & $\begin{array}{c}\text { Redness toe and } \\
\text { feet } \\
(\%)\end{array}$ & $\begin{array}{c}\text { Chicken Leg } \\
\text { Stuck under divider } \\
(\%)\end{array}$ & $\begin{array}{c}\text { Total } \\
(\%)\end{array}$ \\
\hline Roughed & 0.0100 & $0.000 \mathrm{a}$ & $0.0262 \mathrm{a}$ & $0.1042 \mathrm{a}$ & $0.1404 \mathrm{a}$ \\
Smooth & 0.0100 & $0.0031 \mathrm{a}$ & $0.0121 \mathrm{~b}$ & $0.0540 \mathrm{~b}$ & $0.0763 \mathrm{~b}$ \\
SEM & 0.001 & 0.0013 & 0.0018 & 0.0055 & 0.0067 \\
P- value & 0.0001 & 0.1411 & 0.0007 & 0.0002 & 0.0002 \\
\hline $\mathrm{a}-\mathrm{b}$ Means within
\end{tabular}

\section{DISCUSSION}

Chicken box capacity in winter and summer was 100 and 80 chicks, respectively which is in the range of the reported elsewhere (Roberts, 1978). Increased density of chicken more than the standard level will lead to difficulties in supplying fresh air (oxygen). In the study herein we observed that the duration of stay in chicken box at chick room in hatchery was 12 and 7.57 hours in summer and winter, respectively. It have been recommended that travel time from hatching place to rearing farm should not be more than 48 hours (EFSA, 2004; Juul-Madsen and Sørensen, 2004) and even shorter travel times of 12 hours (Mitchell and Kettlewell, 2004). Welfare of farm animals is very important from the aspect of the quality perception of product by consumers (Sundrum, 2001).

Animal welfare approved organization (2010) reported that young birds must be placed within 36 hours of the first egg hatching. Our observation showed that this time is lower than that suggested by this organization.

The space allowance per chick was 2.43 and 1.71 $\mathrm{cm}^{2}$ in summer and winter type chicken boxes, respectively. For one day-old chick, space allowance is 21-25 $\mathrm{cm}^{2}$ per chick (Mitchell and Kettlewell, 2004; EFSA, 2004; Juul Madsen and Sørensen, 2004). Department of Primary Industries (2008) reported that floor space requirement in transport container for one day-old chick were $400-475$ chicks per $\mathrm{m}^{2}$. Our research showed that in summer chicken boxes 80 chicks are kept on $0.258 \mathrm{~m}^{2}$, i.e., 310 chicks per $\mathrm{m}^{2}$ while in winter, 100 chicken on $0.256 \mathrm{~m}^{2}$ or 390 chicks in each $\mathrm{m}^{2}$. Stocking density (i.e. floor surface per chick) is a very important welfare factor which directly and indirectly influences and determines the level of growth of chicken body weight, but it is also related to other welfare indicators such as walking ability or gait score, feathering, incidence and degree of hock burns, foot pad lesions. Stocking density can also affect the biochemical blood parameters such as glucose and total cholesterol concentration and consequently, condition of stress (Skrbic et al., 2009) and performance (Shanawany, 1988). When chickens are placed at higher density, it will affect broiler welfare (Yardimci and Kenar, 2008). An increase in density usually results in corresponding increases in environmental condition such as temperature, humidity, $\mathrm{CO}_{2}$ and ammonia levels leading to the reduced growth and increased incidence of air sac inflammation (Yardimci and Kenar, 2008).

Stressful environmental conditions in early life (Yalçin et al., 2007) and lower than optimum temperature and oxygen affect bone development (Oviedo-Rondón et al., 2008). Low and high eggshell temperatures at incubation decrease relative weights of tibias and high temperatures at late incubation reduce the percentage of relative weights in femurs and shanks (Oviedo-Rondón., 2009). In this study, we aimed to compare the effects of the two kinds of chick papers on leg damages. Smooth paper was light, easy to practice and handling and was packaged hygienically. We observed that the chicks kept on the smooth papers had lower leg abnormality than those kept on the roughed papers.

A high stocking density decreases the income per bird primarily due to the reduction in growth rate, increased proportion of downgraded carcasses, and greater risk of health-related problems (Estevez, 1999). Sorensen et al. (2000) and Garcia et al. (2002) indicated that different forms of dermatitis, breast blister, weakness of legs, are responses to stocking density. Welfare indicators relate to condition of skin (dermatitis, lesions and injuries) and legs and minimal standards in relation to welfare of broilers are focused on space for their walking which is the main prerequisite for development of the locomotive apparatus (Skrbic et al., 2009). In the present study, it was observed that spreading in all space of the chicken box in smooth papers was more than those in rough paper leading to the lower leg problems in chickens kept on the smooth papers.

It is critical to keep chicks well-ventilated to allow for more effective thermoregulation. Muller (1985) reported that minimum ventilation for baby chicks on the ground was $1.68 \mathrm{~m}^{3} / \mathrm{h} / \mathrm{kg}$ and heat production in maintenance state at $30{ }^{\circ} \mathrm{C}$ for chick with $40 \mathrm{~g}$ body weight, was $0.63 \mathrm{~W} /$ chick $(15.8 \mathrm{~W} / \mathrm{kg})$. Minimum ventilation rate in cold weather is $0.019 \mathrm{~L} / \mathrm{s} /$ chick (liters per second per chick) (Tanaka and Xin, 1997). In our first study with summer and winter types of chick box, total ventilation ducts (except the door) was 204.16 and $171.28 \mathrm{~cm}^{2}$, respectively. Hot weather causes an increase in blood vessel diameter to better excrete heat production, blood pressure and heart beat (Java, 2010) and panting of chickens and oxygen requirement is also increased. The need of ventilation 
ducts on surface of chick box needs further investigation. It is recommended to do more research on heat production in high performance commercial strains to design suitable chick box for every strains in hot and cold seasons.

According to Campo et al. (2005), noise seems to affect adversely the productive performance and behavior of the birds. Stadelman (1958a) reported violent behavioral response in young chickens to intermittent sound exposure at 100-118 dB. Sound intensities of $115 \mathrm{~dB}$ were effective in interrupting brooding in hens (Stadelman, 1958b). Chloupek et al. (2009) reported a significant negative effect of acute noise exposure at 80 and $100 \mathrm{~dB}$ in broilers due to a significant increase in corticosterone and cholesterol levels after $10 \mathrm{~min}$ of noise exposure. However, McFarlane and Curtis (1989) reported that plasma corticosterone was unaffected by continuous noise at $95 \mathrm{~dB}$ in female chicks. In the present study, when we put all chicks in the box, they were comfortable in smooth type box. This may be related to the softness and better water absorption in soft papers than the rough types. In the rough type papers, the chicks were noisier and were not comfortable.

\section{CONCLUSIONS}

The rough paper increased both leg damage (defects in motor organs and leg stuck under the box divider) and sound level. Duration of stay in chicken box, allowance space per chicken and total ventilation ducts in the summer type of chicken boxes were 4.4 hours, $29.6 \%$ and $16.1 \%$ more than those for the winter type, respectively. Also age of the flock influenced the sound level in chickens.

\section{REFERENCES}

Animal Welfare Approved Organization (AWA), 2010. Animal welfare approved standards for laying hens and meat chickens. http://www.animalwelfareapproved.org/standards

Arthur, J. 2004. Egg handling from production to set. Aviagen, Hatchery specialist. lecture in june.1.

Campo, J.L., Gil, M.G. Davila, S.G. 2005. Effects of specific noise and music stimuli on stress and fear levels of laying hens of several breeds. Apply Animal Behavior Science, 91:75-84.

Chloupek, P., Voslarova, E., Chloupek, J., Bedanova, I., Pistekova, V., Vecerek, V. 2009. Stress in broiler chickens due to acute noise exposure. Acta Veterinaria Brunesis, 78: 93-98.

Department of Primary Industries, 2001. Code of practice for the land transport of poultry. Bureau of Animal Welfare, Attwood. State Government of Victoria. reprinted 2008. AG0888. http://www.dpi.vic.gov.au/

Estevez, I. 1999. Density: How it can affect the behavior and health of your birds. Maryland
Cooperative Extension, University of Maryland, Fact Sheet 758: 1-8.

European Food Safety Authority (EFSA), 2004. The welfare of animals during transport. Scientific Report of the Scientific Panel on Animal Health and Welfare on a request from the Commission related to the welfare of animals during transport, Adopted March 30, 2004, p. 29. Accessed September 29, 2008. www.efsa.eu.int/cs/

Garcia, R.G., Mendes, A.A., Garcia, E.A., Naas, I.A., Mureira, J., Almedia, I.C.L., Takita, T.S. 2002. Effect of stocking density and sex on feathering, body injury and breast meat quality of broiler chickens. Revista Brasileria de Ciencia Avicola, 4(1):1-9.

Henken, A.M., Van Der Hel, W., Hoogerbrugge, A.C., Scheele, W. 1987. Heat tolerance of one-day old chickens with special reference to conditions during air transport. In: Verstegen MWA and Henken AM (eds), Energy Metabolism in Farm Animals Pages 261-287. Martinus Nijhoff Publishers, Dordrecht, the Netherlands.

Environment Agency (EA), 2005. Technical Guidance Note IPPC SRG 6.02 (farming). IPPC Noise Management at Intensive Livestock Installations. https://www.gov.uk/government/uploads/system/u ploads/attachment_data/file/297085/pmho1105bkd b-e-e.pdf

Java, E. 2010. Stress on the broiler. Campaigning for animal welfare. Indonesia.1-2. www.sac-ina.org.

Joseph, N.S., Moran. J.R. 2005. Effect of flock age and post emergent holding in the hatcher on broiler live performance and further-processing yield. Journal of Applied Poultry Research, 14: 512-520.

Jull-Madsen, H.R, Sorensen, P. 2004. Influence of early or late start of first feeding on growth and immune phenotype of broilers. British Poultry Science, 45(2): 210-222.

Kimo Company, 2010. Sound level meter DB 100. KIMO instruments, User Manual, www.kimo.fr.

King, A.S., Mclelland, J. 1984. Birds their structure and function. Second edition, Bailliere Tindall, London.

Malheiros, R. D., Moraes, V.M.B., Bruno, L.D.G., Malheiros, E.B., Furlan, R.L., Macari, M. 2000. Environmental temperature and cloacal and surface temperatures of broiler chicks in first week post-hatch. Journal of Applied Poultry Research, 9: 111-117.

Mcfarlane, J.M., Curtis, S.E. 1989. Multiple concurrent stressors in chicks 3. Effects on plasma-corticosterone and the heterophillymphocyte ratio. Poultry Science, 68: 522-527.

MitchellI, M.A., Kettlewell, P.J. 2004. Transport of chicks, pullets and spent hens. In: Perry GC (ed), Pages 361-374. Welfare of the Laying Hen. CABI Publishing, Cambridge, MA, UK. 
Muller, W. 1985.Ventilation requirements during air transport of animals. In Proc. of $11^{\text {th }}$ AATA International conference, Tampa, Florida, 29-32.

Oviedo-Rondon, E.O., Small, J., Wineland, M.J., Christensen, V.L., Mozdziak, P.S., Koci, M. D. Funderburk, S. V. L. Ort, D. T., Mann, K.M. 2008. Broiler embryo bone development is influenced by incubator temperature, oxygen concentration and eggshell conductance at the plateau stage in oxygen consumption. British Poultry Science, 49: 666-676.

Oviedo-Rondon, E.O., Wineland, M.J., Small, J., Cutchin, H., Mcelroy, A., Barri, A., Martin, S. 2009. Effect of incubation temperatures and chick transportation conditions on bone development and leg health. Journal of Applied Poultry Research, 18: 671-678.

Pasreform, 2008. Red hocks in day-old chicks or poults. http://www.thepoultrysite.com/articles/1047/redhocks-in-day-old-chicks-or-poults

Paulson, S., Van Dalfsenand, B. 1999. Management of Noise on Poultry Farms. Poultry Factsheet. Ministry of Agriculture and Food. British Columbia.

Roberts, D. 1978. Handling baby chick shipments. In: McWilliam AA (ed.), Animal air transportation-A Global Industry, Proceedings of the Fourth Annual International Meeting, Animal Air Transportation Association, November 6-9. Pages 67-76. Animal Air Transportation Association, Toronto, Ontario, Canada.

SAS Institute, 1999. SAS Procedures Guide. Version 8. SAS Institute Inc., Cary, NC, USA.

Shanawany, M. M. 1988. Broiler performance under high stocking densities. British Poultry Science, 29(1): 43-52.

Skrbic, Z., Pavlovski, Z., Lukic, M., Peric, L., Ilosevic, N. 2009. The effect of stocking density on certain broiler welfare parameters. Biotechnology in Animal Husbandry, 25 (1-2): 1121.

Sorensen, P., Su, G., Kestin, S.C. 2000. Effects of age and stocking density on leg weakness in broiler chickens. Poultry Science, 79: 864-870.

Stadelman, W.J. 1958a. Observations with growing chickens on the effects of sounds of varying intensities. Poultry Science, 37: 776-779.

Stadelman, W.J. 1958b. The effect of sounds of varying intensity on hatchability of chicken eggs. Poultry Science, 37: 166-169.

Statistical Center of Iran (SCI), 2009. Selected Census Results of the Layer Chicken Farms. http://www.amar.org.ir

Tanaka, A., Xin, H. 1997. Effects of structural and stacking configuration of containers for transporting chicks in their micro environment. Transactions of the American Society of Agricultural Engineers, 40(3): 777-782.

Whiteman, C.E, Bickford, A.A. 1988. Avian Disease Manual. American Association of avian Pathologists, 3rd ed. American Association of Avian Pathologist, USA.

Xin, H., Rieger, S.R. 1995. Physical conditions and mortalities associated with international air transport of young chicks. Transactions of the American Society of Agricultural Engineers (ASAE). 38: 1863-1867.

Yalcin, S., Molayoglu, H.B., Banka, M., Genine, O., Pines, M. 2007. Effect of temperature during the incubation period on tibial growth plate chondrocyte differentiation and the incidence of tibial dyschondroplasia. Poultry Science, 86: 1772-1783.

Yardimci, M, Kenar, B. 2008. Effect of stocking density on litter microbial load in broiler chickens. Archiva Zootechnica, 11(3): 75-81. 